\title{
Dimensional analysis revisited
}

\author{
BRUNO GÜNTHER ${ }^{a}$ and ENRIQUE MORGADO ${ }^{\mathrm{b}, \mathrm{c} *}$
}

${ }^{a}$ Professor Emeritus of Physiology and Physiopathology, Universidad de Concepción and Universidad de Valparaíso, Chile

b Programa de Fisiopatología, Facultad de Ciencias Médicas,

Universidad de Santiago de Chile, Santiago, Chile

${ }^{c}$ Programa de Fisiopatología, Instituto de Ciencias Biomédicas, Facultad de Medicina, Universidad de Chile, Salvador 486, Casilla 16038, Santiago, Chile

E-mail: emorgado@machi.med.uchile.cl

\begin{abstract}
The applicability of dimensional analysis (DA) is discussed in relation to the metabolic scaling laws.

The evolution of different theories of biological similarity has shown that the calculated reduced exponents (b) of Huxley's allometric equation are closely correlated with the numerical values obtained from the statistical analysis of empirical data.

Body mass and body weight are not equivalent as biological reference systems, since in accordance to Newton's second law, the former has a dimension of a mass, while the latter should be dimensionally considered as a force $\left(\mathrm{W}=\mathrm{MLT}^{-2}\right)$. This distinction affects the coefficients of the mass exponent $(\alpha)$. This difference is of paramount importance in microgravity conditions (spaceflight) and of buoyancy during the fetal life in mammals.

Furthermore, the coefficients $(B)$ of the length dimension, and $(\gamma)$ of the time dimension do not vary when mass or weight are utilized as reference systems. Consequently, the "specific metabolic time," that results from the ratio of basal oxygen consumption and body mass or body weight yields the "biological meaning" of the time dimension, which is of fractal nature.
\end{abstract}

Key terms: Dimensional analysis. Allometric scaling. Theories of biological similarity. Body mass. Body weight.

\section{INTRODUCTION}

In accordance with Rosen (1983): "the essence of similarity leads to some of the deepest issues in all of science, as for instance when physiological data are compared with theoretical models of mathematical, chemical, physical or biological nature." In the present study, the mathematical model deals mainly with Huxley's (1932) allometric equation (Y = $\left.\mathrm{a} \cdot \mathrm{X}^{\mathrm{b}}\right)$ or of its $\log$ arithmic form $(\log \mathrm{Y}=$ $\log a+b \log X)$, which allowed for the quantitative analysis of the experimental data, in the sense that the numerical value of the allometric exponent (b) permits the characterization of the nature of each of the similarities; for example:

$\mathrm{b}=1 / 3=$ Euclidean length function;

$b=2 / 3=$ Euclidean surface; $\mathrm{b}=3 / 4=$ volume or mass-flow, metabolic rate;

$\mathrm{b}=1 / 4=$ duration of any biological cycle;

$\mathrm{b}=1 / 12=$ velocity;

$\mathrm{b}=-1 / 4=$ frequency of a periodic function;

$\mathrm{b}=-3 / 4=$ total peripheral resistance;

$\mathrm{b}=1$ = mass, volume, or compliance.

Furthermore, it is customary in any quantitative research to compare the predicted values of a given theory with the empirically-determined variables of the corresponding function. Thus, since Rubner's time (1883), the relationship between metabolic rate and body mass has been extensively discussed (Brown and West, 2000; Calder III, 1987; Feldman and McMahon, 1983; Günther, 1975a, 1975b); Günther and Morgado, 1982; Günther et al, 1992; Heusner, 1982; Huxley, 1932; Kleiber, 1975; Lambert and Teissier, 1927;

\footnotetext{
* Corresponding author.
} 
Schmidt-Nielsen, 1997; Sernetz et al., 1985), in particular, his so-called surface rule $\left(\mathrm{V}_{\mathrm{O} 2}=\mathrm{k} \cdot \mathrm{M}^{2 / 3}\right)$. More recently, Heusner (1983, 1984, 1985, 1986, 1987, and 1988) has re-examined the validity of the abovementioned two- third mass exponent as related to metabolic scaling laws in mammals. Butler et al. (1987, 1988) later came to the conclusion that in Heusner's publications the dimensional analysis (DA) was employed incorrectly and that metabolic scaling laws cannot be deduced directly from DA. This conclusion was shared by Prothero (2002), who stated verbatim "that DA is unlikely to provide explanations applicable to scale-up in diverse species." Nevertheless, Heusner (1987) has insisted that, in accordance with Lambert and Teissier's (1927) first theory of biological similarity, Newton's reduction coefficient $\left(\chi=\mu^{\cdot \alpha} \cdot \lambda^{\beta} \tau^{\gamma}\right)$ is a dimensionless number, because $\mu, \lambda$ and $\tau$ are the ratios between prototypes (p) and models (m), with regard to the three-dimensional system of physics $(\mathrm{M}, \mathrm{L}, \mathrm{T})$, because $\mathrm{M}_{\mathrm{p}} / \mathrm{M}_{\mathrm{m}}=\mu$; $\mathrm{L}_{\mathrm{p}} / \mathrm{L}_{\mathrm{m}}=\lambda$; and $\mathrm{T}_{\mathrm{p}} / \mathrm{T}_{\mathrm{m}}=\tau$.

We agree with Butler et al. $(1987,1988)$ and Prothero (2002), that DA per se is unable to predict the allometric exponents (b) of Huxley's (1932) allometric equations, both for morphological and for physiological variables, due to the fact that DA is a sine qua non step for the subsequent theories of biological similarity.

In the history of western science, the principle of similarity initially appeared in Euclidean geometry and later in Newton's mechanics, which is based on two postulates (Table I). The first assumed the same density $(\rho=M / V)$ in prototype and model, and the second, that the acceleration of gravity $(\mathrm{g}=$ $\mathrm{L} \cdot \mathrm{T}^{-2}$ ) is a physical constant on earth (Table I, item 1). When Lambert and Teissier (1927) applied the theory of a mechanical similarity to living beings, they observed a discrepancy between the theoretical predictions and the empirical findings, and for that reason the above-mentioned authors replaced the second postulate with an a priori assumption, namely that the time ratio $(\tau)$ should vary in proportion with the length ratio $(\lambda)$, as shown in Table I, item 2. It is also worth mentioning that years later, McMahon (1973) and McMahon and Bonner (1983) postulated another theory of similarity of mechanical nature, the so-called theory of "elastic

TABLE I

Description of the basic postulates for three theories of similarity

\begin{tabular}{|c|c|c|}
\hline Item & Theory of similarity & The corresponding postulates \\
\hline \multirow[t]{6}{*}{1} & Mechanical & $\begin{array}{l}\text { First postulate: "The density }(\rho) \text { is the same in prototype (p) and } \\
\text { model }(\mathrm{m}) \text { ", thus, } \rho_{\mathrm{p}} / \rho_{\mathrm{m}}=1\end{array}$ \\
\hline & & $\rho=M / V \quad \rho=M \cdot L^{-3} \quad L=M^{1 / 3}$ \\
\hline & & and $\gamma=\mu^{1 / 3}$ \\
\hline & & $\begin{array}{l}\text { Second postulate: "The acceleration of gravity }(\mathrm{g}) \text { is the same in } \\
\text { prototype }(\mathrm{p}) \text { and model }(\mathrm{m}) \text { ": } \mathrm{g}_{\mathrm{p}} / \mathrm{g}_{\mathrm{m}}=1\end{array}$ \\
\hline & & $\mathrm{g}=\mathrm{L} \cdot \mathrm{T}^{-2} \quad \mathrm{~L}=\mathrm{T}^{2}$ \\
\hline & & and $\tau=\lambda^{1 / 2}=\mu^{1 / 6}$ \\
\hline \multirow[t]{2}{*}{2} & Biological & First postulate: The same as in the mechanical similarity \\
\hline & & $\underline{\text { Second postulate }(A P R I O R I):} \tau=\lambda=\mu^{1 / 3}$ \\
\hline 3 & Elastic & $\begin{array}{l}\text { Instead of one length dimension (L), it is postulated that two length } \\
\text { dimensions should be considered: one lineal (l) and one transverse } \\
\text { (d), besides Young's elastic modulus (E'), the density }(\rho) \text {, and the } \\
\text { acceleration of gravity }(g) \text {. }\end{array}$ \\
\hline
\end{tabular}


similarity," by assuming the existence of two length dimensions, one longitudinal (1) and other transverse (d), at right angles to the former (Table I, item 3), where $1=\mathrm{d}^{2 / 3}$, and also by adding Young's elastic modulus $(E ')$ or the "stress/strain ratio."

This theory is only valid for Bovidae and not for all terrestrial mammals. Furthermore, the $3 / 4$ power law is applicable to small aquatic animals and even to unicellular organisms (Hemmingsen, 1960) which, due to the effects of buoyancy are not significantly affected by gravitational forces as implied in the theory of elastic similarity (Li, 2000).

A general comparison of the theoretical exponents obtained by similarity and experimental theories was performed by Günther et al. (1992), based on the proposals of Yates (1979) from the statistical analysis of 203 allometric equations concerning twelve different biological functions of mammals, where the following coefficients for the exponent of mass, length and time were obtained: $\mathrm{b}=0.958 \cdot \alpha+0.346 \cdot \beta+$ $0.296 \cdot \gamma$ while Lambert and Teissier (1927) postulated the following equation in order to obtain the allometric exponent: $\mathrm{b}=\alpha+$ $1 / 3 \cdot \beta+1 / 3 \cdot \gamma$. Similar results to those of the present study have been obtained by West et al. (1997) utilizing an entirely different approach, which is based on re-engineering living beings.

The relevance of DA in theoretical biology is confirmed if we consider the possibility of utilizing body mass or body weight as independent reference systems in allometry. This conceptual duality allows us to predict the allometric exponent of various functions of mammalian fetuses (Mortola, 1987, 2001; Günther and Morgado, 2002 and 2003) as well as of organisms submitted to microgravity, or else to quantify the maximal body size of terrestrial animals (Günther et al., 2002).

\section{A DUAL REFERENCE SYSTEM IN BIOLOGY: BODY MASS OR BODY WEIGHT}

A direct consequence of the application of dimensional analysis to biological variables has been the distinction between the physical notion of mass and weight, which were established originally by Isaac Newton's second law (F $=\mathrm{m} \cdot \mathrm{a}$, where $F$ is force, $m$ is mass and $a$ an acceleration). With the advent of the space-flight era and of the organisms exposed to microgravity conditions, body weight (W) measured on earth was replaced by body mass $(\mathrm{M})$.

The dimensional difference between mass and weight is also based on Newtonian postulates, in the sense that $\mathrm{W}=\mathrm{M} \cdot \mathrm{g}$, where $\mathrm{g}$ is the acceleration of gravity on earth (at the sea level $\left.\mathrm{g}=9.8 \mathrm{~m} \cdot \mathrm{s}^{-2}\right)$. On the other hand, the dimensions of $\mathrm{g}$ are $\left[\mathrm{L} \cdot \mathrm{T}^{-2}\right]$, and by applying the corresponding equivalences of $\mathrm{L}$ and $\mathrm{T}$ as functions of mass, we obtain $\mathrm{L} \alpha \mathrm{M}^{1 / 3}$ and $\mathrm{T} \alpha \mathrm{M}^{1 / 4}$, which yields the acceleration of gravity corresponding to $\mathrm{M}^{1 / 3} \cdot \mathrm{M}^{-2 / 4}=\mathrm{M}^{-1 / 6}$. Therefore the Newtonian force $(F)$ is $\mathrm{M} \cdot \mathrm{g}$, or else $\mathrm{M}^{1} \cdot \mathrm{M}^{-1 / 6}=\mathrm{M}^{5 / 6}=$ $M^{0.83}$ (Günther and Morgado, 2003).

\section{CHANGES IN BASAL HEART RATES DURING SPACE FLIGHTS IN MAN}

The long-term acclimation of heart rate to microgravity was studied by Gundel et al. (2002) by means of sleep polygraphs during non-REM sleep on a cosmonaut who stayed aboard for 438 days. A lengthening of the average beat-to-beat interval was observed, which corresponded to a reduction of the heart rate by approximately $20 \%$, while during the first month of spaceflight the lengthening of the R-R interval was only $82 \mathrm{~ms}$ and $94 \mathrm{~ms}$ after 6 months. The difference between the spaceflight conditions and the ECG-measurements on ground primarily concern the physical dimensions, because in one instance we are dealing with body mass and in the second with body weight, in accordance to the following equations

$$
b_{M}=\alpha+1 / 3 \beta+1 / 4 \gamma
$$

and for body weight as the reference system

$$
b_{\mathrm{W}}=5 / 6 \alpha+1 / 3 \beta+1 / 4 \gamma
$$

The essential difference between these two equations is located at the coefficients of the mass exponent $(\alpha)$. As for instance, for the metabolic rate, whose dimensional equivalence is $\left[\mathrm{ML}^{2} \mathrm{~T}^{-3}\right]$, in one case we 
obtain the following numerical value as a function of body mass:

$$
\mathrm{b}=1+2 / 3-3 / 4=11 / 12 \sim 0.091
$$

and in the other instance, as a function of body weight:

$$
b=5 / 6+2 / 3-3 / 4=3 / 4=0.75
$$

On the other hand, "the specific metabolic time" introduced by Schmidt-Nielsen (1984) is given by the ratio of the metabolic rate and the corresponding body mass:

$$
\mathrm{b}=11 / 12-1=-1 / 12 \sim-0.091
$$

and, in the other case:

$$
\mathrm{b}=3 / 4-1=-1 / 4=-0.25
$$

Therefore, the coefficients (q) for the length exponent $(B)$ and $(r)$ for the time exponent $(\gamma)$ are identical; the only difference appears in the corresponding coefficients $(p)$ for the exponents of body mass $(\alpha)$, which as mentioned above is 1 for body mass and 5/6 for body weight, being $1 / 6(0.17)$, the numerical difference between the two exponents. Since we are dealing with logarithmic expressions, the antilogarithm of 0.17 is 1.47 , which means that the numerical difference between mass and weight should only yield a $47 \%$ difference in the corresponding coefficients of the allometric exponents $(\alpha)$. In this context, it is worth mentioning that the coefficient for the time exponent $(\gamma)$ is always the same (1/4 for fractal times), as postulated by Sernetz et al. (1985) and by West et al. (1997). The main distinction between microgravity (space flights) and earth gravity $\left(9.8 \mathrm{~m} \cdot \mathrm{s}^{-1}\right)$ is correlated with the change of one physical dimension, namely $[\mathrm{M}]$ in one case and is $\left[\mathrm{MLT}^{-2}\right]$ in the other.

Finally, in mammals these physical differences are notorious at birth, since the prenatal physical dimension of fetal mass after delivery is converted to the reference variable body weight during the entire postnatal life, as illustrated in Figure 1 for the duration of cardiac cycles before and after birth (data from Altman and Dittmer, 1964).

From a series of allometric equations of empirical origin dealing with morphological or physiological characteristics, it is possible to calculate invariant numbers (IN), which are not only dimensionless $\left(\mathrm{M}^{0} \mathrm{~L}^{0} \mathrm{~T}^{0}\right)$ and numerically the same among different species (interspecies), but also when these IN are compared in intraspecies investigations, as for instance, in humans, the values obtained from newborns are the

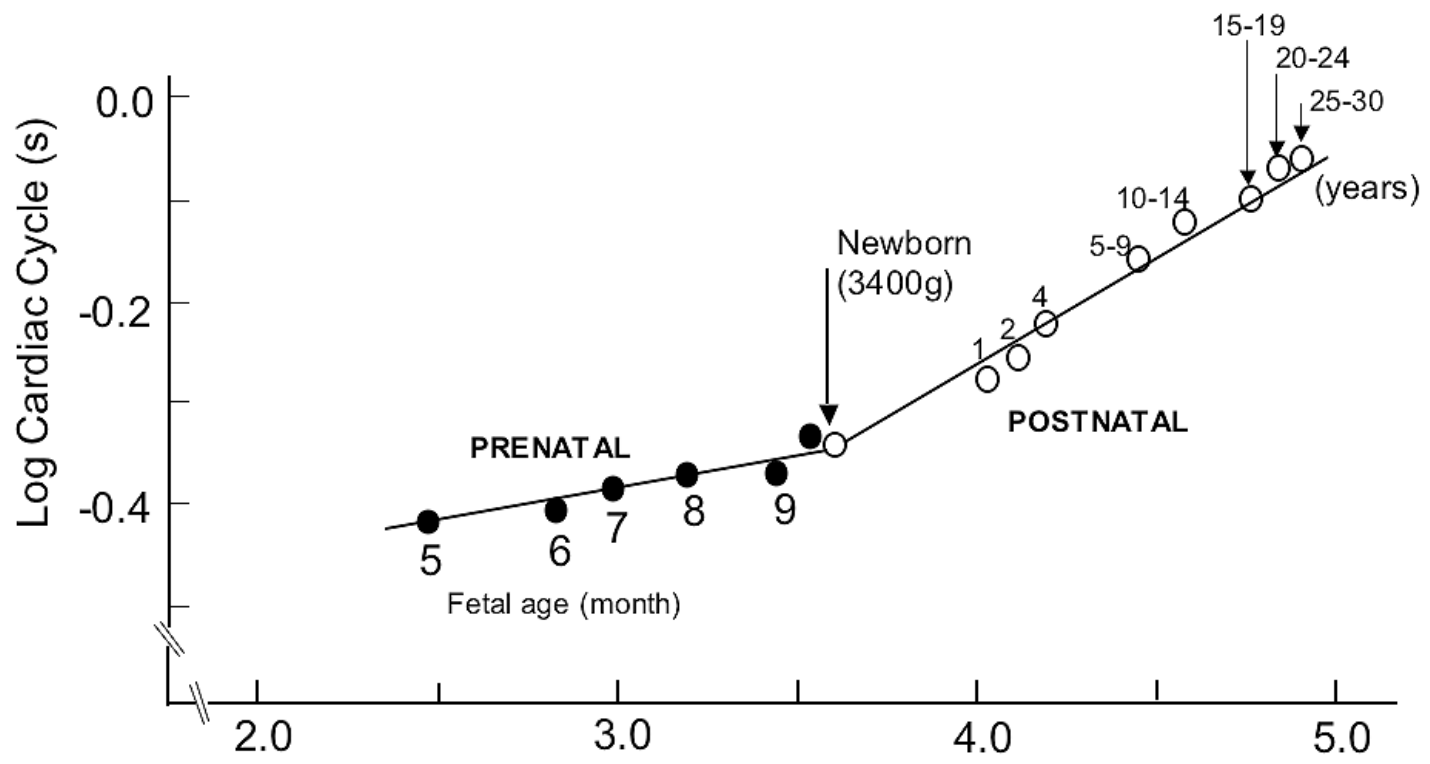

Log Body Weight (g)

Figure 1: Double logarithmic plot of the duration of each cardiac cycle (s) as function of body weight (g), during prenatal and postnatal periods of human beings. 
same of the adult specimens (Günther and Morgado, 2002).

The dilemma concerning mass and weight, which is the most convenient reference system in biological science, could be studied when seven different cardiorespiratory functions were compared in adult mammals and during fetal or neonatal life (Günther and Morgado, 2003). In the fetal condition, the fetal body weight in utero was significantly reduced due to the effect of buoyancy, which nearly yielded the condition of body mass, in analogy with the effects of microgravity during space flights.

It is worth mentioning that the dimensional difference between mass and weight has never been considered in the biological sciences, despite the fact that the DA is based on the mass dimension, while in experimental biology, body weight is always the variable that is actually determined. If this dimensional difference is taken into account, the predictability of the allometric exponent improves notably (Günther and Morgado, 2003).

\section{THE FRACTAL NATURE OF PHYSIOLOGICAL TIME}

As is well known, mankind has been measuring the course of time for more than 5,000 years as the solar day, the lunar month, and the solar year, inventing for this purpose the sundial, the water clock, the physical pendulum, and more recently the quartz-crystal clock, and finally the atomic clock, such as the cesium-133 fountain clock, with a precision of $10^{-15}$ seconds.

In contrast to the "absolute" time scales, which are valid for the physical sciences, beginning with Newton's "Tempus absolutum, verum et mathematicum", the size-dependent relative time or the "physiological" time scale is of paramount importance for the life history of all living beings. As shown in Figure 2, while the body weight range of homeotherms comprises around six decades, the physiological time scale corresponds to almost ten decades, beginning with the duration of a fast muscle contraction up to the duration of life (Calder III, 1984). It is worth mentioning that the slope of all allometric equations dealing with biological time functions is almost identical $(b=0.25$ +/- 0.0099), as postulated by Sernetz et al. (1985) and West et al. (1997), a selfsimilarity or a scale invariance, which is characteristic for fractal mechanisms. The same conclusion has already been obtained by Goldberger (1997) while comparing the normal human heart rate oscillation in function of time, for example, during 300 minutes, 30 minutes, or finally 3 minutes.

The replacement of Lambert and Teissier's (1927) 1/3 exponent for the time dimension $(\mathrm{T})$ by the $1 / 4$ exponent of fractal nature meant a real improvement of the predictive capacity of all subsequent theories of biological similarity.

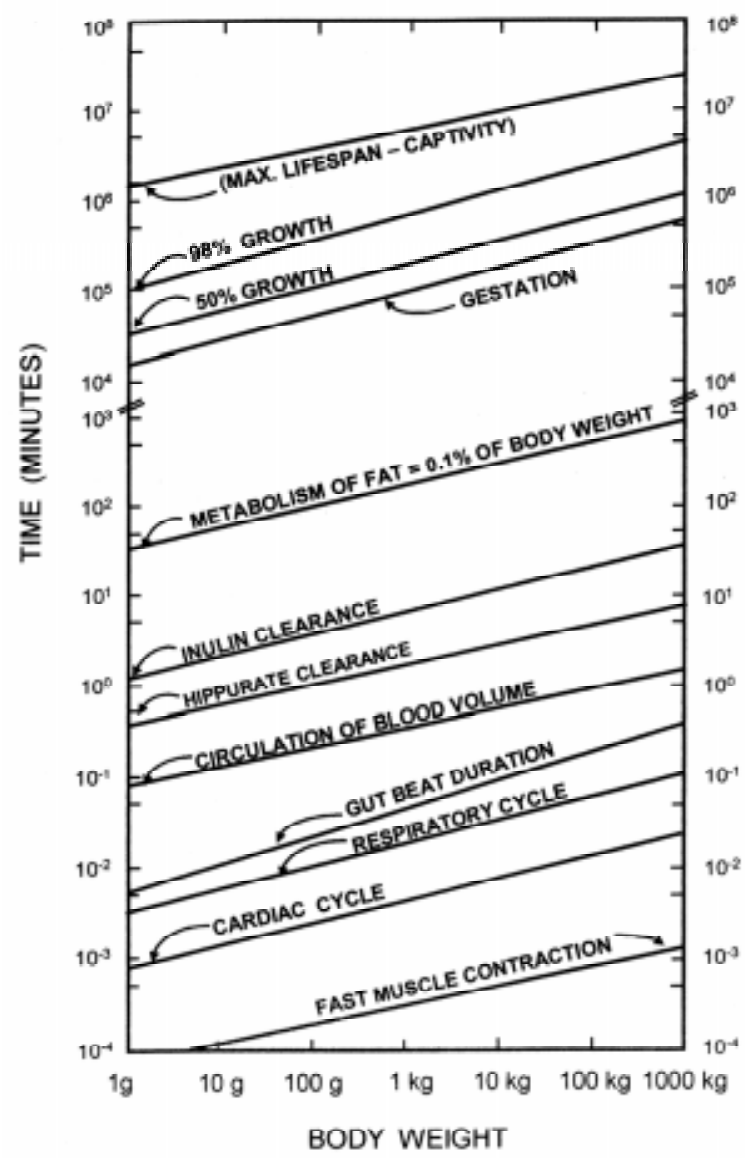

Figure 2: Double logarithmic plot of biological time functions as related to body weight (Modified from Calder, 1984). 


\section{REFERENCES}

ALTMAN PL, DITTMER DS (1964) Biological Data Book. Federation of American Societies for Experimental Biology. Washington, DC

BROWN JH, WEST GB (2000) Scaling in Biology. Oxford, UK: Oxford University Press

BUTLER JP, FELDMAN HA, FREDBERG JJ (1987) Dimensional analysis does not determine a mass exponent for metabolic scaling. Am J Physiol 253: R195-R199

BUTLER JP, FELDMAN HA, FREDBERG JJ (1988) Replay to "A theory of similitude may predict a metabolic mass exponent.” Am J Physiol 255: R351R352

CALDER III WA (1984) Size, Function and Life History. Cambridge, MA: Harvard University Press

CALDER III WA (1987) Metabolic allometry: basic correlations are independent of units when properly converted. J Theor Biol 128: 523-524

FELDMAN HA, MCMAHON TA (1983) The $3 / 4$ mass exponent for energy metabolism is not a statistical artifact. Respir Physiol 52: 149-163

GOLDBERGER AL (1997) Fractal variability versus pathological periodicity: complexity loss and stereotypy in disease. Persp Biol Med 40: 543-561

GUNDEL A, DRESCHER J, SPATENKO YA, POLYAKOV VV (2002) Changes in basal heart rate in spaceflights up to 438 days. Aviat Space Environ Med 73: 17-21

GÜNTHER B (1975a) Dimensional analysis and theory of biological similarity. Physiol Rev 55: 659-699

GÜNTHER B (1975b) On theories of biological similarity. Fortschr Exper Theor Biophys 19: 1-111

GÜNTHER B, MORGADO E (1982) Theory of biological similarity revisited. J Theor Biol 96: 543-559

GÜNTHER B, GONZALEZ U, MORGADO E (1992) Biological similarity theories: a comparison with the empirical allometric equations. Biol Res 25: 7-13

GÜNTHER B, MORGADO E (2002): An invariant number of the respiratory system of mammals: newborn and adult. Respir Physiol 130: 327 - 331

GÜNTHER B, MORGADO E, KIRSCH K, GUNGA H-C (2002): Gravitational tolerance and size of the largest land animals. Geologische Mitteilungen of the Museum of Natural History: 5, 263-267

GÜNTHER B MORGADO (2003) Body mass and body weight: a dual reference system in biology. Rev Chil Hist Nat 75: $57-64$

HEMMINGSEN AM (1960) Energy metabolism as related to body size and respiratory surfaces and its evolution. Rep Steno Mem Hosp 4: 1-110

HEUSNER AA (1982) Energy metabolism and body size. I) Is the 0.75 mass exponent of Kleiber's equation a statistical artifact? Respir Physiol 48: 1-12
HEUSNER AA (1983) Body size, energy metabolism, and the lungs. J Appl Physiol 54: 867-873

HEUSNER AA (1984) Biological similitude: statistical and functional relationships in comparative physiology. Am J Physiol 246: R839-R845

HEUSNER AA (1985) Body size and energy metabolism. Ann Rev Nutr 5: 267-293

HEUSNER AA (1986) Energy metabolism and body size. II) Dimensional analysis and energetic non-similarity. Respir Physiol 48: 13-25

HEUSNER AA (1987) What does the power function reveal about structure and function in animals of different size? Ann Rev Physiol 49: 121-133

HEUSNER AA (1988) A theory of similitude may predict a metabolic mass exponent. Am J Physiol 255: R350R351

HUXLEY JS (1932) Problems of Relative Growth. London: Methuen

KLEIBER M (1975) The Fire of Life. Huntington: Krieger

LAMBERT R, TEISSIER G (1927) Theorie de la similitude biologique. Ann Physicochim Biol 3: 212-246

LI J K-J (2000) Scaling and invariants in cardiovascular biology. In: BROWN JH, WEST GB (eds) Scaling in Biology. Oxford, UK: Oxford University Press. pp: 113-128

MCMAHON T (1973) Science and shape in Biology. Sci 179: $1201-1204$

MCMAHON TA, BONNER JT (1983) On Size and Life. New York. Scientific American Library

MORTOLA JP (1987) Dynamics of breathing in newborn mammals. Physiol Rev 67: 187- 243

MORTOLA JP (2001) Respiratory Physiology of Newborn Mammals. A Comparative Perspective. Baltimore, MD: John's Hopkins University Press

PROTHERO J (2002) Perspectives on dimensional analysis in scaling studies. Persp Biol Med 45: $175-189$

ROSEN R (1983) Role of similarity principles in data extrapolation. Am J Physiol 244 (Regulatory Integrative Comp Physiol 13): R591 - R599

RUBNER M (1883) Ueber den Einfluss der Körpergrösse auf Stoff - und Kraftwechsel. Z Biol 19: 535 - 562

SCHMIDT-NIELSEN K (1984) Scaling. Why is Animal Size so Important? Cambridge, U K: Cambridge University Press

SCHMIDT-NIELSEN K (1997) Animal Physiology. Adaptation and Environment. Cambridge, UK: Cambridge University Press

SERNETZ M, GELLÉRI B, HOFFMANN J (1985) The organism as bioreactor. Interpretation of the reduction law of metabolism in terms of heterogeneous catalysis and fractal structure. J Theor Biol 117: 209-239

WEST GB, BROWN JH, ENQUIST B J (1997) A general model for the origin of allometric scaling laws in biology. Sci 276: 122-126

YATES FE (1979) Comparative physiology compared to what? Am J Physiol 237: R1-R2 